\title{
Design and application of location error teaching aids in measuring and visualization
}

\author{
Fengning $\mathrm{Yu}{ }^{1, \mathrm{a}}$, $\mathrm{Lei}_{\mathrm{Li}}{ }^{1}$, Jian Guo ${ }^{1}$, Songman Mai ${ }^{1}$, Jiashun Shi ${ }^{1}$ \\ ${ }^{1}$ Northeastern University in Shenyang. Liaoning, China
}

\begin{abstract}
As an abstract concept, 'location error' in $<$ Machinery Manufacturing Technology $>$ is considered to be an important element with great difficult to understand and apply. The paper designs and develops an instrument to measure the location error. The location error is affected by different position methods and reference selection. So we choose position element by rotating the disk. The tiny movement transfers by grating ruler and programming by PLC can show the error on text display, which also helps students understand the position principle and related concepts of location error. After comparing measurement results with theoretical calculations and analyzing the measurement accuracy, the paper draws a conclusion that the teaching aid owns reliability and a promotion of high value.
\end{abstract}

\section{Introduction}

At present, engineering colleges in China explain related contents to location error analysis and calculation with the assistance of PPT and CAI as teaching aids, lacking of visible location error analysis model. Location error is relatively abstract in practical production, especially when positioned with cylindrical surface, the position reference axis cannot be observed, which is difficult for students to make further understanding about calculation principle of location error. As a result, it is necessary to develop a set of visualized teaching aids of location error for machine manufacturing teaching.

\section{Location error analysis}

\subsection{Concept of location error}

Processing error will arise in workpiece location. Under the condition of adjustment method processing, the maximum position variation of process standard in the direction of working size resulted from workpiece positioning is called location error which is signified with $\Delta_{D W}$. The location error includes datum mismatch error $\Delta_{J B}$ and datum displacement error $\Delta_{J W}$. The location error resulted from inconformity between position standard and process standard is called datum mismatch error. The location error resulted from subsidiary manufacturing error of position and location error resulted from its fit clearance are called datum displacement error.

\footnotetext{
a Corresponding author: 951650724@qq.com
}

\section{2 excircle positioning mode and typical location error analysis}

There are two kinds of position modes of outside surface: centralized positioning and bearing positioning. The positioning standard of centralized positioning is axial lead of external cylindrical surface with the commonly used positioning device being spring head. The commonly used positioning device of support positioning is $\mathrm{V}$-Block. The thesis adopts different types of position modes, and selects different process standards for finished surfaces of workpiece to make location error analysis and comparison, which can be more comprehensive. The simple instruction about location error calculation will be made with the example of $\mathrm{V}$ piece in the following contents.

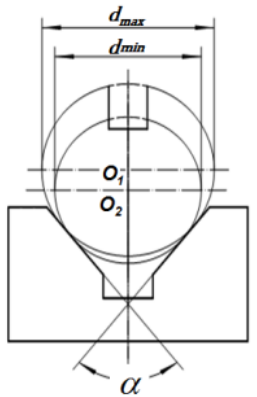

(a)

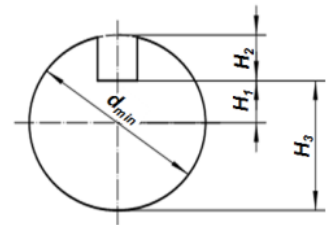

(b)
Figure 1. location error analysis of workpiece in $\mathrm{V}$ piece

Like in 2-1 picture, mill keyway in workpiece. Take the horizontal plane where central line of workpiece lies as 
the positioning standard, whose standard displacement error being:

$$
\Delta_{j w}=\frac{T_{d}}{2 \sin (\alpha / 2)}
$$

Including $\mathrm{T}_{d}$ as diameter tolerance of workpiece When adopting three kinds of process standards, the corresponding location error calculation is showed in table 1 .

Table 1 location error analysis of workpiece in $\mathrm{V}$ piece

\begin{tabular}{|l|l|l|l|}
\hline $\begin{array}{l}\text { Process } \\
\text { standard }\end{array}$ & $\begin{array}{l}\text { Process } \\
\text { size }\end{array}$ & $\begin{array}{l}\text { datum mismatch } \\
\text { error } \Delta_{\mathrm{NW}}\end{array}$ & Location error $\Delta_{\mathrm{Dw}}$ \\
\hline $\begin{array}{l}\text { Central- } \\
\text { line }\end{array}$ & $\mathrm{H}_{2}$ & 0 & $T_{-} d /(2 \sin (\alpha / 2))$ \\
\hline Up-bus & $\mathrm{H}_{2}$ & $T_{-} d / 2$ & $T_{-} d /(2 \sin (\alpha / 2))+T_{-} d / 2$ \\
\hline Down-bus & $\mathrm{H}_{2}$ & $T_{-} d / 2$ & $T_{-} d /(2 \sin (\alpha / 2))-T_{-} d / 2$ \\
\hline
\end{tabular}

\section{Design scheme of visualized teaching aids of location error}

The teaching aids designed in the thesis are aimed to gain location error stated in above contents through measurement. As a result, the teaching aid should possess functions like generation, measurement, and display of location error. The teaching aids designed by the thesis are mainly composed by mechanical part, measuring part and control part, like in figure 2 .

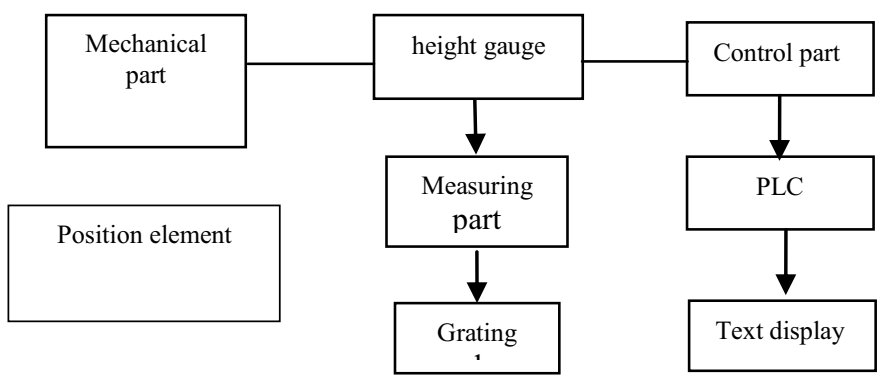

Figure 2. asic composition of teaching aids

\section{Mechanical structure design and three-dimensional modeling and simulation of location error teaching aids}

\subsection{Positioning parts and selection of workpiece}

When choosing positioning parts, the diversity of location error should be sufficiently considered. So we choose VBlock, 'L' bearing, semicircle sleeve and spring-clip to show different location mode. In order to observe the tiny change in position error, we design two workpieces of large dimensional tolerances. The diameter of two workpieces are $18 \mathrm{~mm}$ and $20 \mathrm{~mm}$, thus they own a dimensional tolerance of $2 \mathrm{~mm}$.

\section{2 switching mechanism design of positioning parts}

In order to select different kinds of position element, we refer to indexing plate to design structure. We choose position element by rotating the disk. Then fix the disk to bracket by index pin, to make sure the plate won' t move a tiny displacement during the experiment. After that, we fix position element to disk by bolts and locating pin. We also use the compression screw installed on the axle to clamp the workpieces.

The two-dimensional assembling of location error teaching aids designed by the thesis is showed in figure 3 .
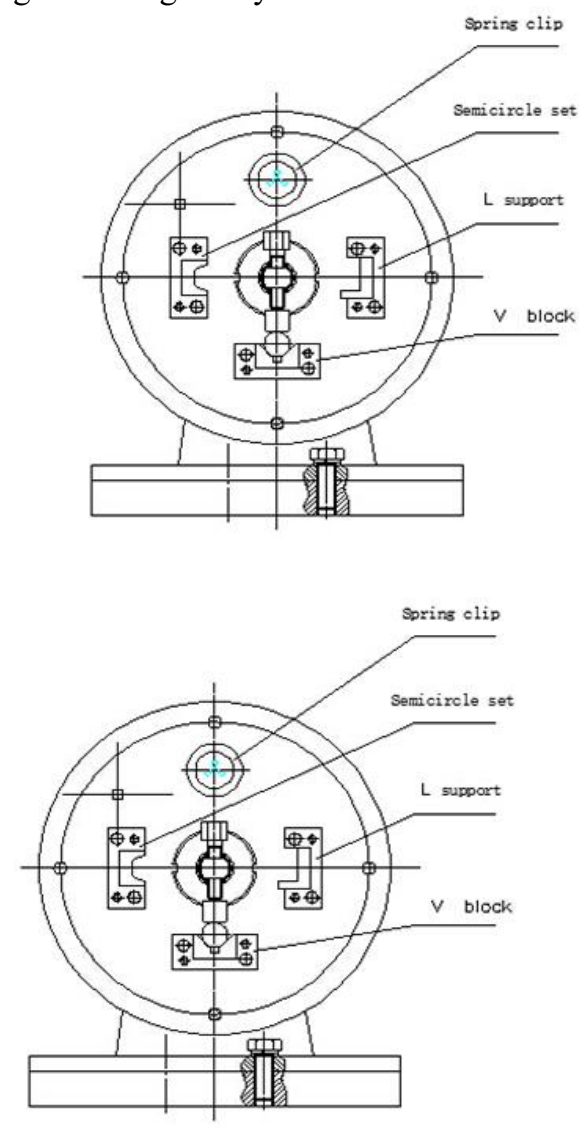

Figure 3.sembling aids picture of location error teaching aids

\section{3 measurement mechanism design of location error}

We connect height gauge to grading ruler so as to transfer the tiny movement from the location of scriber to grading sensor. By adjusting the location of scriber, we obtain the up-bus, down-bus and the axis position of workpieces.

\subsection{Three dimensional modeling and simulation of location error teaching aids}


After finishing design of location error analysis, make three-dimensional modeling with SolidWorks software. In addition, motion simulation is made to guarantee the usability of device.

\section{Design for measurement and control system and operation interface of location error teaching aid}

\section{1 function of the location error teaching aid}

Function1: Select different kinds of workpieces (we take two different sizes of cylinders for example)

Function2: Switch to various position element (we illustrate how V-block works in the experiment)

Function3: Process basis selection

Function4: Position Measurement - we get the location error based on up-bus and down-bus of workpieces.

Function5: Data process and display (location error, datum mismatch error, datum displacement error can be visualized on the test display.)

\subsection{Design of hardware and software for measurement and control system}

\subsubsection{Grading ruler selection}

Location error teaching aid performs a series of operations by using grading ruler to measure the tiny movement and the text display to show the data. The grading ruler can transmit signal to PLC, utilizing highspeed counter to enumerate. It could give a clear presentation of movement and its accuracy can reach up to $5 \mu \mathrm{m} .[5][6]$

\subsubsection{Test display selection}

We choose cost-effective and easy connection test display as HMI to show results. It is of great economical and practical, and the programming is of great convenient. 5.2.3 PLC (programmable logic controller) selection S7-200PLC has an advantage over rapidity, accuracy and stability. As a result, we take it as the control unit based on economy and well performance of its nuclear-CPU224. [7]

The measurement and control section of teaching aid can be divided into four system unit. Figure 4 shows the transitive relation of data and signal.

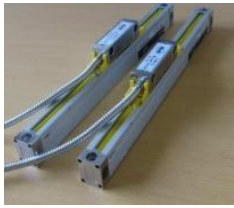

(1)grading ruler

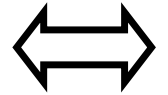

Fixture

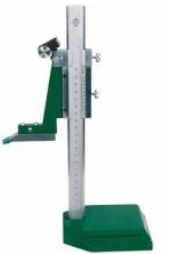

(2)height gauge

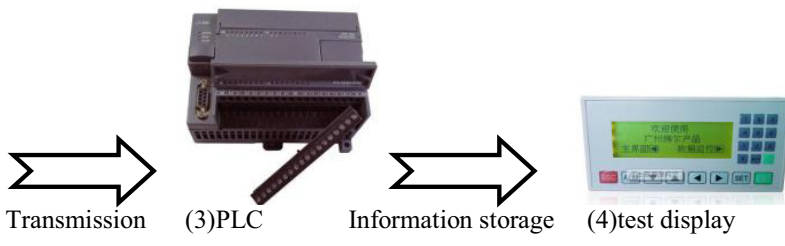

Figure 4.odule components

The grading ruler will transform a tiny movement to an electrical signal, then transmit the signal to PLC when measuring the position of process basis. After simple operation of location error, the system transports the relevant data to the test display. The series make structure clear and simple.

\section{Take V-block as a position element to do location error experiments}

Figure 5 shows the location error teaching aids we developed. Through joint commissioning of hardware and software, we make the aids operate normally and meet the requirements. We select $\$ 18 \mathrm{~mm}$ and $\$ 20 \mathrm{~mm}$ position element to do location error experiment. We compare the measuring actual value $\Delta_{\mathrm{JB}} 、 \Delta_{\mathrm{JW}} 、 \Delta_{\mathrm{DW}}$ to the theoretical value, in order to verify the feasibility and accuracy of teaching aids.

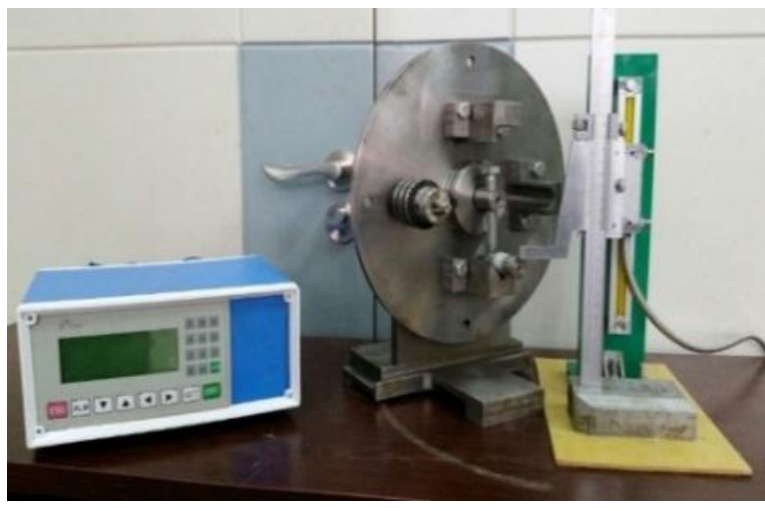

Figure 5 teaching aid of location error

\subsection{Measure the position of process basis}

During the experiment of location error, Adjustment Act is regarded as a prerequisite. By selecting different process bases and measure the position of them, we obtain the actual values of location error,

Table 2 and table 3 show the result of the first set of experiment, table 2 and table 3 show the result of the second set of experiment, the theoretical results are displayed in table 4. Besides, workpiece1 is a cylinder with a diameter of $18 \mathrm{~mm}$, and workpiece 1 is a cylinder with a diameter of $20 \mathrm{~mm}$. 
Table 2. the first set of experiment of position size

\begin{tabular}{|l|c|c|c|}
\hline Work piece & $\begin{array}{c}\text { Display of up- } \\
\text { bus by } \\
\text { grating/5 } \mathrm{um}\end{array}$ & $\begin{array}{c}\text { Display of } \\
\text { down-bus by } \\
\text { grating } / 5 \mathrm{um}\end{array}$ & $\begin{array}{l}\text { Display of } \\
\text { center by } \\
\text { grating } / 5 \mathrm{um}\end{array}$ \\
\hline workpiece1 & $117 t$ & -2433 & -628.5 \\
\hline workpiece2 & 1665 & -2356 & -343.5 \\
\hline
\end{tabular}

Table 3 the first set of experiment of measurement error

\begin{tabular}{|c|c|c|c|}
\hline $\begin{array}{c}\text { Pype of error } \\
\text { Process basis position }\end{array}$ & $\begin{array}{c}\text { Center } \\
/ 5 \mu \mathrm{m}\end{array}$ & $\begin{array}{c}\text { down-bus } \\
/ 5 \mathrm{~mm}\end{array}$ & $\begin{array}{c}\text { up-bus } \\
/ 5 \mu \mathrm{mm}\end{array}$ \\
\hline$\Delta_{\mathrm{JE}}$ & 0 & 208 & 208 \\
\hline$\Delta_{\mathrm{JW}}$ & 285 & 285 & 285 \\
\hline$\Delta_{\mathrm{DW}}$ & 285 & 77 & 493 \\
\hline
\end{tabular}

Table 4 the second set of experiment of position size

\begin{tabular}{|c|c|c|c|}
\hline Work piece & $\begin{array}{c}\text { Center } \\
/ 5 \mu \mathrm{m}\end{array}$ & $\begin{array}{c}\text { down-bus } \\
/ 5 \mathrm{\mu m}\end{array}$ & $\begin{array}{c}\text { up-bus } \\
/ 5 \mathrm{\mu m}\end{array}$ \\
\hline workpiece1 & $145 t$ & -2145 & -344.5 \\
\hline Workpiece2 & $194 \mathrm{C}$ & -2061 & $-60 \mathrm{5}$ \\
\hline
\end{tabular}

Table 5 the second set of experiment of measurement error

\begin{tabular}{|c|c|c|c|}
\hline Type of error & $\begin{array}{l}\text { Center } \\
/ 5 \mathrm{um}\end{array}$ & $\begin{array}{c}\text { down-bus } \\
/ 5 \text { mm }\end{array}$ & $\begin{array}{l}\text { up-bus } \\
/ 5 / \mathrm{\mu m}\end{array}$ \\
\hline$\Delta_{\mathrm{JE}}$ & 0 & 200 & 200 \\
\hline$\Delta_{\mathrm{fW}}$ & 284 & 284 & 284 \\
\hline$\Delta_{\mathrm{DW}}$ & 284 & 84 & 484 \\
\hline
\end{tabular}

Table 6 the theoretical results

\begin{tabular}{|l|l|l|l|l|l|}
\hline \multicolumn{2}{|l|}{$\begin{array}{l}\text { center as the } \\
\text { process basis/5um }\end{array}$} & \multicolumn{2}{l|}{$\begin{array}{l}\text { up-bus as the } \\
\text { process basis/5um }\end{array}$} & \multicolumn{2}{l|}{$\begin{array}{l}\text { down-bus as the } \\
\text { process basis } / 5 \mathrm{um}\end{array}$} \\
\hline$\Delta_{\mathrm{JE}}$ & 0 & $\Delta_{\mathrm{JE}}$ & 200 & $\Delta_{\mathrm{JE}}$ & 200 \\
\hline$\Delta_{\mathrm{JW}}$ & 280 & $\Delta_{\mathrm{JW}}$ & 280 & $\Delta_{\mathrm{JW}}$ & 280 \\
\hline$\Delta_{\mathrm{DW}}$ & 280 & $\Delta_{\mathrm{DW}}$ & 80 & $\Delta_{\mathrm{DW}}$ & 480 \\
\hline
\end{tabular}

\subsection{Processing and analysis of measurement data}

Take an average of $\Delta_{\mathrm{IB}} 、 \Delta_{\mathrm{JW}} 、 \Delta_{\mathrm{DW}}$ measured in two experiments, table 5 shows the averaged errors.

Table 7 the average of two experiments

\begin{tabular}{|c|c|c|c|c|c|}
\hline \multicolumn{2}{|c|}{$\begin{array}{c}\text { center as the } \\
\text { process basis } / 5 \mathrm{um}\end{array}$} & \multicolumn{2}{c|}{$\begin{array}{c}\text { up-bus as the } \\
\text { process basis } / 5 \mathrm{~mm}\end{array}$} & \multicolumn{2}{c|}{$\begin{array}{c}\text { down-bus as the } \\
\text { process basis } / 5 \text { um }\end{array}$} \\
\hline$\Delta_{\mathrm{JE}}$ & 0 & $\Delta_{\mathrm{JE}}$ & 204 & $\Delta_{\mathrm{JE}}$ & 204 \\
\hline$\Delta_{\mathrm{JW}}$ & 284.5 & $\Delta_{\mathrm{JW}}$ & 284.5 & $\Delta_{\mathrm{JW}}$ & 284.5 \\
\hline$\Delta_{\mathrm{DW}}$ & 284.5 & $\Delta_{\mathrm{DW}}$ & 80.5 & $\Delta_{\mathrm{DW}}$ & 488.5 \\
\hline
\end{tabular}

6.3 Comparison and analysis between experimental values and theoretical values of location error
Compare the experimental results with the theoretical result and calculate the absolute difference of location error, results are as follows.

Table 8 absolute difference of location error

\begin{tabular}{|c|c|c|c|c|c|}
\hline \multicolumn{2}{|c|}{$\begin{array}{c}\text { center as the process } \\
\text { basis } / \mathrm{mm}\end{array}$} & \multicolumn{2}{|c|}{$\begin{array}{c}\text { up-bus as the } \\
\text { process basis/mm }\end{array}$} & \multicolumn{2}{|c|}{$\begin{array}{l}\text { down-bus as the } \\
\text { process basis } / \mathrm{mm}\end{array}$} \\
\hline$\delta_{\text {Law }}$ & 0.0225 & $\delta_{\Delta g w}$ & 0.0025 & $\delta_{\Delta \mathrm{gw}}$ & 0.0425 \\
\hline$\%_{\Delta \text { Dw }}$ & $1.6 \%$ & $\%_{\Delta v w}$ & $0.6 \%$ & $\%_{\Delta v w}$ & $1.7 \%$ \\
\hline
\end{tabular}

By comparison, we keep the difference of location error less than $0.05 \mathrm{~mm}$, and successfully control the relative error under $2 \%$, which tests and verifies authenticity of the results as well as the ability of experimenting of the teaching aid.

\section{Measurement accuracy of location error teaching aid}

The cooperative relationship of assembling and the manufacture of dimensional tolerances among each part, will make an impact on the measurement precision of the grading ruler. So it is necessarily to construct dimensionchain analysis of the teaching aid.

$A_{0}$ - the closed-loop regarded as the final form of loop during assembling process, the distance from the scriber plane of height gauge to the level.

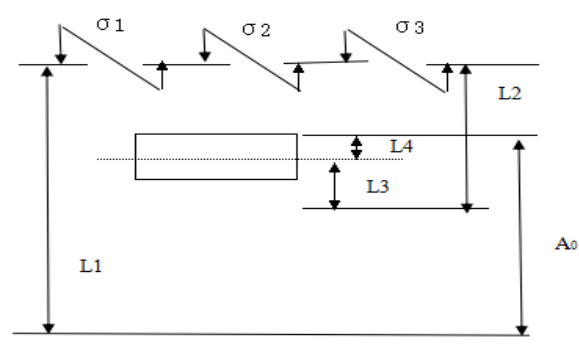

Figure 6. dimension-chain of V-block location error

The definition and accuracy requirements of composing link are as follows:

$\mathrm{L}_{1}$ - the distance from horizontal plane to the centerline of hole on mounting plate with a dimensional tolerance of $0.1 \mathrm{~mm}$.

$\sigma_{1}$ - the deviation from the centerline of disk to the centerline of hole on mounting plate with a concentricity error of $0.1 \mathrm{~mm}$.

$\sigma_{2}$ - the deviation from the axis of mandrel to the centerline of disk with a concentricity error of $0.05 \mathrm{~mm}$.

$\sigma_{3}$ - the deviation from the centerline of disk to the axis of bearing with a concentricity error of $0.1 \mathrm{~mm}$.

$\mathrm{L}_{2}$ - the distance from the axis of bearing to the bottom of V-block, with a dimensional tolerance of $0.15 \mathrm{~mm}$.

$\mathrm{L}_{3}$ - the distance from the bottom of V-block to the centerline of work piece, with a dimensional tolerance of $0.1 \mathrm{~mm}$ 
$\mathrm{L}_{4}$ - the radius dimension of the workpiece, with a dimensional tolerance of $0.1 \mathrm{~mm}$.

The functional relationship between closed-loop and composing link is

$A=L_{1}-L_{2}+L_{3}+L_{4}-\sigma_{1}-\sigma_{2}-\sigma_{3}$

After taking total derivative for the equation of dimension-chain, we get

$d A=\frac{\theta f}{\theta L_{1}} d L_{1}+\frac{\theta f}{\theta L_{2}} d L_{1}+\frac{\theta f}{\theta L_{3}} d L_{1}+\frac{\theta f}{\theta L_{4} 6} d L_{1}+$ $\frac{\theta f}{\theta \sigma_{1}} d \sigma_{1}+\frac{\theta f}{\theta \sigma_{2}} d \sigma_{2}+\frac{\theta f}{\theta \sigma_{3}} d \sigma_{3}$

Plugging the values into the formula, we obtain $d A=0.1-0.05-0.1+0.1+0.1+0.1-2 * 0.05-$ $0.1=0.05 \mathrm{~mm}$

According to the formula of linear closed-loop, we get the dimensional tolerances of $0.05 \mathrm{~mm}$. From the experiment, we get the location error of $1.42 \mathrm{~mm}, 0.4 \mathrm{~mm}$, $2.44 \mathrm{~mm}$, corresponding to the process basis based on upbus, center and down-bus. The dimensional tolerance of closed-loop is less than $15 \%$ of the minimum of the location error. For that case, we can testify the reliability and authenticity of the results.

\section{Conclusion}

The teaching aid that we invent has simple structure and can be operated conveniently. Besides, with the help of its demonstration and measurement, location errors can be visualized. The aid has following characteristics:

\subsection{Visualization of location error}

Strong conceptual location errors can be reflected by experiment. A direct demonstration of location error helps students get profound understanding in its principles and knowledge.

\subsection{High accuracy}

Grating scale as a highly sensitive device can reach the accuracy of $5 \mathrm{um}$. Remarkably enhance the resolution ratio and obtain more reliable measuring results. It proves the reasonableness and accuracy of the teaching aid by comparing the location error between experiments and theory calculation.

\subsection{Apply to different kinds of locate modes and procedure sizes}

The location error teaching aid use different kinds of locate mode. Not only can measure and show different kinds of location errors with different locate modes, but also analyze location errors of different workpieces in different procedure sizes with the same locate mode. It is a fully functioning device.

In conclusion, the teaching aid fills in the blank of practical observation of location errors. Positive reviews are received from the students after demonstrating the aid in class. This shows that the aid is valuable for application and popularization. It is an ideal aid for location error's teaching in class.

\section{References}

1. WenLin Liu, CaiHua Xiong. Location error model of fixture. Journal of Huazhong University of Science and Technology, 2003, 07(2):72-74.

2. Jie Sun, ZhiPing Liu. Apply and practice in the experiment of measuring and analyzing location error. Laboratory Science, 2007, 02(4):99-101.

3. DaLei Li, XiaoJie Wang, YanPing Zheng. Discussion about essence and calculating ways of positioning error. Mechanical Engineer, 2005, 09(3):92-93

4. Syamsul H, Oiwa T, Tanaka T, etal. Location error improvement based on ultrasonic oscillation for a linear motion rolling bearing during sinusoidal motion . Precision Engineering, 2014, 38(3): 617627.

5. Yu Wang. The integration of theory and practice apply in mold teaching. Agricultural Technology and Equipment, 2014, 09:91-92.

6. KeZhen Han,QuanYing Sun,HongYun Wang.The research of measurement with grading displacement sensor based on PLC.Journal of Harbin University of Science and Technology.2005,05:43-45.

7. Yi Xun, Junxiong Zhang, Wei Li, Weiguo Cai. Automatic System of Seeds Refined Grading Based on Machine Vision . Intelligent Control and Automation, 2006, 2 (4):9687-9689.

8. Padmanaban, Saravanan. Exact grading of multiple path delay faults. Design, Automation and Test in Europe Conference and Exhibition, 2002(2):84-88.

9. Duan, Mingyang. Analysis of solving assembly size chain with modification methods. Jixie goneheng Xuebao, 1999(1): 96-102. 